\title{
An Integrative-Relational Approach in Schizophrenia: from Philosophical Principles to Mentalization-Based Practice
}

João G. Pereira and Martin Debbané

\begin{abstract}
In this paper, we explore psychosis and schizophrenia as prototype disturbances, where mentalizing failures are widely seen. We attempt to describe how the process of rekindling mentalizing within attachment relationships (here, the patient-therapist relationship) can have a protective effect not just on the onset of the disturbance, but also when psychosis is already actively installed. We star by discussing mentalizing in training, practice and supervision. We also try to understand it contextually, as a relational concept, within the history of psychological therapies.
\end{abstract}

Key-Words: mentalizing, psychosis, relational, integrative

\section{Introduction}

Mentalizing is a generic psychological process activated when thinking about intentional mental states underpinning human actions. Scholarly work on the concept of mentalizing involves both theoretical elaborations of the mind-brain relationship, as well as empirically-based psychotherapeutic approaches to clinical work and supervision. Most importantly perhaps, the process of mentalizing in psychotherapy is fostered through a type of stance, attitude, or attentional set towards patients and clinical material. For this reason, we discuss mentalizing in training (section 2), practice and supervision (sections 3 and 4). Mentalizing is, par excellence, a relational concept which is usefully applied in clinical practice when understood contextually within the history of psychological therapies (Section 1). In the final sections, we explore psychosis and schizophrenia as prototype disturbances, where mentalizing failures are widely seen. We attempt to describe how the process of rekindling mentalizing within attachment relationships (here, the patient-therapist relationship) can have a protective 
effect not just on the onset of the disturbance, but also when psychosis is already actively installed.

\section{From One-Person Psychology to Two-Person Psychology}

Theories and practices of psychotherapy involve a number of different perspectives on the patient, as well as on the therapeutic relationship; it is perhaps the evolving view of the therapist's role, from being an expert-observer to being an actor subject to intersubjective and interpersonal dynamics, that is most relevant to our overall attempt in transitioning from philosophical values to practical considerations in psychotherapy. We ask this question as a starting point: in clinical practice, what is the relevance of taking into account the person of the therapist? We will try to summarize how the person of the therapist became increasingly important in psychotherapy writings and practice. We will focus particularly on psychoanalysis as the starting point and ground for the contemporary landscape considering the critical role of the therapist in psychotherapeutic treatment.

From a practical standpoint, the person of the therapist has always been important. It seems rather obvious to think that the personal values, personality and working style of the therapist are relevant to the process and outcome of therapy. However, psychoanalytic theory and literature have significantly evolved in the last 70-80 years with regards to the involvement of the therapist in the process of therapy as a participating self. Most authors now agree that these changes have represented paradigm shifts (Gilbert and Orlans, 2011).

Briefly charting some of the main historical turning points in conceptions of the therapist's role in treatment, we may start with Freud's Drive Theory, where the role of the analyst was seen as bringing the patient's unconscious memories and wishes to conscious awareness: "where id was ego shall be" (Freud, 1933). The mind was seen as an apparatus of contradictory forces and impulses, tensions and discharges, with biology playing a major role in motivating behaviour. From the beginning of experimental treatment using hypnosis to the creation and growth of the psychoanalytic cure, the role of the analyst was conceived as that of a detached scientist, trying to incur changes in the patient's mind.

The neutrality, anonymity and abstinence rules in Freud's psychoanalytic method aimed to put at bay any influence coming from the person of the therapist, her/his 
personality, values and opinions. Most importantly perhaps, Freud perceived the affective stimulation provoked by the therapeutic encounter as something that could blur the analyst's mind, and consequently negatively affect his work with patients. Given the intimate nature of the psychoanalytical work proposed by Freud, he was also keenly aware that enactments could potentially hurt the very enterprise of having psychoanalysis recognized as a valid form of treatment. In this context, Freud placed transference entirely in the patient's mind, and advised rather rigidly that analysts keep aside any reactions they may have to the therapeutic encounter by adopting the traditionally distant, other-focused analytical stance. He was given to observe intense struggle, to put it lightly, in his colleagues who regularly broke the orthodox rules.

It is now recognized by most streams in psychoanalysis that the orthodox stance is impossible, and that it might even contribute to enactments if the analyst's experience is not included in the dynamics that call for analysis in a psychoanalytic treatment. Although the psychoanalytic developments that followed changed focus in keeping with general Freudian rules, a rich and creative debate emerged concerning the ubiquity of transference / countertransference phenomena, and how specific definitions of these concepts affect the analytic method.

The concept of counter-transference, i.e. the therapist's affective response when materiel brought by the patient activates the therapist's unconscious, has gained legitimacy, transitioning from being characterized as unhelpful and something to avoid, to being perceived as fundamental tools in therapy (see Pereira, 2010 for a critique). We are now practicing psychotherapy in what is known as the full "relational turn" (e.g. Aron, 1996; Mitchel, 2000; Ghent, 1989) with the intersubjective and relational schools claiming the full presence of the therapist as an essential ingredient for change. Concepts from phenomenological and existential schools were integrated in psychoanalysis and terms such as spontaneity, authenticity, contextual meaning, attunement or relational field began to come to the forefront. A number of different contemporary schools of psychotherapy have become more sensitive to phenomena that stem from the concept of counter-transference, but that may be operationalized differently. What we wish to point out is how counter-transference phenomena are increasingly seen, by different brands of therapy, as a valid source of knowledge that, instead of burdening the therapist, may actually help in furthering intersubjective understanding of what is at play in therapy. Given that counter-transference responses have to do with the therapist "as a person", we now discuss how personal values and assumptions in psychotherapy can also play a role in training and practice. 


\section{Personal Values and Assumptions in Psychotherapy Training and Practice}

In contemporary psychotherapy training, most trainees are encouraged to review personal values and philosophical assumptions in order to understand their impact on patients and therapeutic work. While training encourages such a profound revision of one's position to others and to the world, it is in the clinical struggle to understand and help patients, and particularly with patients suffering from psychosis, that this revision becomes nothing less than a necessity.

Drawing on Sartre (1992), our therapeutic endeavour is to relate to others with respect, very much in relation to the inescapable responsibility of assuming one's own actions and choices. If there is an enactment or a clear impasse in the therapeutic relationship we strive to reach enough humility to examine and take responsibility for our own contributions to the situation, and aim to remain available to explore the possible misunderstandings leading to the current relationship knot (Pereira, 2015). The profession of psychotherapy offers a tremendous opportunity to learn from experience, for both patient and therapist, in the context of that which is exchanged in a therapeutic relationship.

From the point of view of the Mentalization Based Treatment (MBT) clinician, the foundations for curiosity about other people's motivations, feelings and intentionality comes from the clinician's own experience of having felt understood at times of relational impasse in their personal lives. Their own experience of having been met by someone else's mind opens up to learning about self and other as an essential means for discovering the social world (see the concept of bio-social feedback in Fonagy et al, 2002). Learning about self and other is an essential ingredient for discovering separateness, paving the practitioner's way to value the patients' autonomy and, even perhaps, taking pleasure in observing hidden potential being unravelled. This possible gratification, however, is not the aim but the result of a relational process where the therapist allows him/herself to be moved and impacted by the vicissitudes of the client and the therapeutic relationship. It is notably through being involved and sustaining the client's involvement that the therapist can make herself/himself available to discover the client's being (Heidegger, 1962).

The genuine interest about the other can be referred to as non-voyeuristic curiosity. We recognize the complex nature of human beings by taking a position of humility and inquiry (Pereira, 2010). The therapeutic stance is one of not knowing, but interested in finding out; it is modelled on secure attachment behaviours between caregiver and 
infant (Fonagy et al, 2002). The interest of the caregiver in the child as a social agent with a mind promotes the development of epistemic trust (Fonagy and Alison, 2014), the special kind of trust that promotes the infant's interest in acquiring knowledge from others and from the social world. Indeed, the infant is faced with an overwhelming wealth of sources of knowledge, and tends to trust the perspective brought by individuals who engage him/her as a meaningful agent. The attuned curiosity and interest manifested within the therapeutic encounter models this process that proceeds through a humble recognition of intersubjectivity and reciprocal mutual influence, instantiating a "psychological field formed by interacting worlds of experience" (Stolorow and Atwood, 1992, p. 3).

In (good) relational psychotherapy training, humility is transversal, not only within relationships but also regarding interventions, modalities and schools. We are saying three things here: a) that no single model of psychotherapy can fully explain psychic phenomena, b) that each model, even "Grand Narratives" such as the CognitiveBehavioural Approach or Psychoanalysis, offer partial views of human beings, and c) that we sit in the position of negotiating within a multitude of diverse views. The MBT therapist is not interested in creating a new treatment modality but in finding out what works for the patient. Quoting Badiou (1989, p84) "the announcement of the 'End of the Grand Narratives' is as immodest as the Grand Narrative itself".

Coming back to the issue of training, the psychotherapy trainee learns after the first years of exposure to the depth of the human psyche, that attempting to describe experience in neatly organized concepts is problematic. Language itself is an activity where words merge with one another in a fuzzy way (Wittgenstein, 1953). Whilst we see merit in many contemporary approaches, it is not uncommon to watch the polarization that each model creates when defending its own territory. This process leads to unnecessary dichotomisation and over-specification of therapeutic models (and this includes our own model, the mentalization-based model). A key point in maintaining the process of organizing experience while being affected by new experience and knowledge is to never forget that most things are fuzzy, opposed and tense, in the same way that language presents itself, and not dissimilar to the opacity of minds. In clinical training, we would thus support a dynamic and integrative, nondichotomized view of self and other, which most importantly needs to work through the therapist's biases when experiencing intense emotional arousal that typically triggers interpretative patterns characterized by certainty (see non-mentalizing modes in Bateman, Fonagy and Luyten 2012). 
In advocating such a fundamental engagement to uncertainty, we also risk moving towards radical integrative and postmodern frameworks where truth itself is challenged. Although these positions are understandable, if taken to the extreme, they risk becoming closer to solipsism or even nihilism. Knowledge, in this way, would never be possible. We advocate that knowledge is possible but that it is dependent on a constructive process, and thus requires being constantly the subject of review, modification and challenge.

In striving to be helpful to patients, one may find it useful to extend awareness of self and other to contextual awareness. One may assume the role of psychological therapist consciously, whilst also being aware of the unconscious dynamics that underlie the performing of roles (Goffman, 1959). Conscious psychotherapists are sensitive to (but not overburdened) the power inherent in assuming a role under the umbrella of official organizations (state hospitals, public trusts, etc.) and sheltered by professional bodies (Pereira, 2015). In a Foucauldian sense, therapists carry the power-knowledge of these institutions and the discourse of mental illness (Foucault, $1972 ; 1975)$, and thus keen awareness of such contextual determinants may help to remove some of the obstacles to a better understanding of the patient's subjective experience.

Drawing on philosophical values promoting the inherent co-dependency in learning the psyche within the context of psychotherapy, we outline how orienting the trainees' minds to appreciate the opacity and complexity of mental states may assist in sustaining a psychotherapeutic process. A keen awareness of one's position at various levels of the psychotherapeutic endeavour (intersubjective, interpersonal, social, sociohistorical) may safeguard against certainty, and help foster in the patient the sense of being understood, or more minimally perhaps, being the subject of another's mind, which in development has been found to represent a key process in the rise of an autonomous, agentive self. Building on this transition from philosophy to psychology, we now focus more specifically on mentalization as a psychological process sustaining mental health.

\section{Mentalization: a relational, developmental, and integrative framework}

After having contextualized the importance of the relationship and of the therapist as a participating, reflective self, we will now focus on the concept of Mentalization. We briefly outline its relevance to psychopathology and clinical practice, and further focus 
on its relevance to psychosis and schizophrenia. So, what is mentalization or, as we prefer to say because it is an active process, mentalizing?

Mentalizing can be defined in several different ways but we will start by stating what can be seen as the absence of mentalizing: mind-blindness. Baron-Cohen (1995) asks us, in referring to autism, to imagine what our world would be like if we were aware of physical things but were blind to the existence of mental things. He meant of course blind to things like thoughts, beliefs, knowledge, desires, and intentions, which for most of us self- evidently underlie behaviour. If the reader can imagine this for a moment, then she/he would have a glimpse of what mentalization is: implicitly and explicitly interpreting the actions of oneself and others as meaningful on the basis of intentional mental states (e.g. desires, needs, feelings, beliefs and reasons). This is just one way of defining mentalizing, which is also exemplified by other characterizations: to see ourselves from the outside and others from the inside; understanding misunderstanding; having mind in mind (binding heart and mind) (Allen, Fonagy and Bateman, 2008). The concept is also comparable to many others (Choi-Kain and Gunderson, 2008), such as empathy (mentalizing the other), mindfulness (mentalizing the self), social cognition (cognitive mentalizing), and metacognition (thinking about thinking), etc.

Along the years, the psychoanalytic literature has proposed a number of conceptual cousins before mentalization was taken up by Pierre Marty and the French School of Psychosomatics. Freud's Bindung, translated to English as binding or linking, was first formulated in the 1895's 'Project for a Scientific Psychology' as the mental activity of linking psychic instinctual energy in primary process with mental 'representation' in secondary process (Freud, 1895). Reformulated along the years, this concept referred to the transformation of somatic non-mental activity into something mental, through the creation and adaptation of networks of thoughts that can metabolize mental pathogens such as developmental stress, loss, personal challenges and help defuse the toxicity of trauma.

Initially, Freud (1914) stressed that the representation of internal states could fail in various ways, which somewhat resonates with what is meant nowadays by mentalizing impairments. Other concepts, such as Melanie Klein's depressive position (Klein, 1945) or Wilfred Bion's (1962) alpha-function are consistent with the mentalizing process (Fonagy et al, 2002). For authors from the clinical domain, the construct of mentalizing rests upon the psychoanalytic insight which permeates virtually all schools of psychoanalysis, proposing that the mother-child relationship provides both the space 
and the process through which the development capacity to symbolize can emerge. For example, the consolidation of the true self in Winnicott (1962) or the acquisition of empathy in Kohut (1977), are clearly dependent on the caregiver's psychological understanding of the infant. Winnicott (1962) also recognized, alongside Kohut (1977) and Fairbairn (1952) that the psychological self develops through the perception of oneself in another person's mind as thinking and feeling (Fonagy et al, 2002).

In the 1960s, French psychoanalysts employed the concept of mentalization to understand psychosomatic patients who displayed a lack of symbolization of somatic states (Marty, 1968; 1991). The construct of alexithymia has also demonstrated some overlap with aspects of mentalizing, specifically relating to self-awareness (Goerlich et al, in preparation). Fonagy (1991: p.641) introduced mentalization into Anglophone psychoanalytic discourse by defining it as the capacity to conceive of conscious and unconscious mental states in oneself and others'. The contemporary clinical application of mentalization has been developed in great part by Fonagy and colleagues at the University College London (UCL) and the Anna Freud Centre. The group's current conceptualization of mentalization combines insights and ideas derived from (Jurist, Slade and Bergner, 2008):

- (a) attachment theory and research about the properties of early (and potentially also later therapeutic) relationships that promote, or hinder, the capacity for mentalization;

- (b) Developmental psychology and philosophy;

- (c) Contemporary neuroscientific research about the brain and the link between brain and mind, as well as about the way early relationships affect development;

- (d) Psychoanalysis, and in particular the application of W.R. Bion's writings on learning from experience.

Within the above principles, Bateman and Fonagy $(2004 ; 2006)$ have developed a treatment programme for Borderline Personality Disorder (BPD), a condition intimately linked with attachment difficulties, affect dysregulation and mentalizing failures. This treatment programme was given the name Mentalization-Based Treatment, currently applied to psychotherapy for personality disorders (MBT; Bateman and Fonagy, 2016). 


\section{Mentalizing as a resilience-inducing process}

A considerable amount of enthusiasm has propelled clinicians and clinical scientists trained in the MBT model for BPD to apply and adapt their model to other diagnostic categories, such as antisocial personality disorder (ASPD; Bateman et al, 2016), eating disorders (Jewell et al, 2015), functional somatic disorders (Luyten et al, 2012) and other disorders (Bateman and Fonagy, 2012). Psychotic disorders (Weijers et al, 2016; Brent, 2009) and their preceding clinical high-risk states (Debbané et al, 2016; Debbané et al, 2016a) have also been proposed as potential therapeutic targets for which mentalization-based treatment may yield therapeutic effects. Most of these adaptations still require significant research to uphold the promise they offer, and their veritable clinical utility will be a subject of inquiry for the coming decade. The reason why MBT may be adaptable to different disorders is rather simple: mentalizing is conceptualized as a protective factor mitigating the negative effects of risk factors such as interpersonal stress, but also the consequences of psychopathological manifestations. Mentalization thus intervenes at different stages of illness from early risk states to full-blown clinical states (Debbané et al, 2016). An important point to remember is that mentalizing is not conceived as an aetiological factor leading to the onset of psychiatric disorders, but rather a protective resilience-inducing process that individuals at high-risk, or clinically-ill individuals, may more adaptively employ to attenuate risk and/or temper the interpersonal and functional costs of psychopathology.

How then does a process such as mentalizing provide a protective effect to psychopathology? The current working hypothesis stipulates that higher order cognition processes (HOC; Rudrauf, 2014; Fonagy \& Bateman, 2016; Debbané et al, 2016), those imaginative processes that sustain thinking about self and others, mentalizing oneself in relation to others and the world, and perspective-taking encompassing past, present and future, provide the plasticity and flexibility that prevent thinking patterns from crystallizing into pathological, rigid forms of relating to oneself and others.

Hypothetically, mentalizing may be relevant in high-risk or prodromal states of psychopathology because it guards the individual from the establishment of circular, impoverishing, and self-reinforcing pathological thinking processes. Importantly, mentalizing is a process that is sustained not only within one's relationship to oneself (self-reflection), but perhaps more importantly through communication with meaningful others. In this way mentalizing is both developmentally dependent upon the quality of early attachment relationships, as well as upon secondary attachments which are crucial to life transitions and coping with life stress. Mentalizing relationships breeds 
trust and faith in relationships, and contributes to seeing others as potentially bringing novel, complementary and meaningful perspectives to one's own views. This process, which is active both at the intersubjective and interpersonal level, prevents the individual from succumbing to circular, often binary, rigid patterns of thoughts characteristic of psychopathological states. In situations where psychopathology has set in, the progressive rekindling of mentalizing through therapeutic encounters and the amelioration of communication with significant others can yield positive effects and help the suffering individual to gain more consistent access to resources available in the therapeutic environment and beyond, namely in her/his interpersonal and social networks. Below, we will specify how this hypothesis may be specifically articulated around risk for psychosis and psychotherapy along the psychosis spectrum.

\section{Mentalization-Based Practice along the Psychosis Continuum}

A first conceptualization for an MBT framework to psychosis was introduced by Brent and Fonagy (2014). The authors proposed a developmental model wherein early attachment disturbances play a role early in the unfolding of psychosis vulnerability. These attachment disturbances may originate from different sources. Firstly, environmental factors such as child abuse and neglect (Read and Gumley, 2010) may yield insecure or disorganized attachment which makes the child more prone to employ dissociative coping mechanisms in the face of high emotional arousal, and to potentially deactivate attachment needs; both phenomena are thought to impact the early hypothalamic-pituitary-adrenergic (HPA) function, as well as thwart the oxytonergic systems sustaining synchrony in early attachment relationships. Additionally, both these environmentally-induced vulnerabilities can impact the dopaminergic reward system, and potentially affect the integrity of the salience system as the child and adolescent develops and acquires the rudimentary social cognitive skills required to navigate in the social world.

Of course, environmental risk factors necessarily interact with genetically endowed vulnerability to develop psychotic spectrum disorders. To clarify, we are not advocating that attachment insecurity causes schizophrenia, but rather, that genetic risk for psychosis unfolds by developmental transactions with social learning as well as epigenetic cycles. Here, the construct of schizotypy is useful in that it provides a developmental model that integrates genetic-environment transactional processes. Schizotypy is commonly understood as a personality trait which reflects a type of 
nervous system functioning that prototypically sustains the expression of cognitive disorganization, perceptual aberrations, as well as affective and interpersonal impairments. It reflects an underlying genetic vulnerability to develop psychotic disorders, although the genetics, neurobiology, and neurophysiology components are not yet understood. Whether from a taxonic or dimensional point of view, vulnerability to develop psychosis unfolds "hand in hand" with environmental risk factors, and only a fraction of individuals at-risk go on to develop psychotic disorders. Our point is to conceive of how the development and use of mentalizing may participate in preventing individuals from becoming clinically ill, and in those with a diagnosed disorder, how mentalizing could help mitigate the adverse effects of psychopathology.

\section{Mentalizing at Different Stages of Unfolding Psychosis}

The emergence of psychotic disorders is commonly thought to proceed in 4 stages. In the first premorbid stage, usually occurring from early development until late adolescence, special attention is paid to sub-clinical soft-signs of psychosis proneness in the neurological and neuromotor domains, as well as clinically in terms of schizotypal manifestations in the interpersonal, perceptual and cognitive domains. More recently, some studies have attempted to draw links between these manifestations and the development of mentalizing skills. A number of studies (reviewed in Debbané et al, 2016) have highlighted subtle but apparent mentalizing impairment in domains such as reality monitoring (Debbané et al, 2009; 2010) and theory of mind (Clemmensen et al, $2014 ; 2016)$. Interestingly, the adequate development of social cognitive skills, such as theory of mind, seems to be associated with the natural disappearance of early psychotic signs such as auditory verbal hallucinations (Barthels-Velthuis et al. 2011). Later in adulthood, individuals who hear voices (voice hearers), but who do not suffer from or meet criteria for a psychotic disorder, demonstrate superior mindfulness skills in comparison with both clinically ill voice hearers and healthy controls (Peters et al, 2016). Although a sufficient amount of longitudinal data is still lacking, the available results are consistent with a resilience-inducing model of social cognitive processes that sustain the understanding of oneself and others as driven by intentional mental states. This warrants the establishment of primary prevention strategies sustaining the developmental building blocks of social cognition (Debbané and Barrantes-Vidal, 2015). 
The second stage in the emergence of psychotic disorders has been revealed by longitudinal studies following prodromal or ultra high-risk adolescents and young adults (Yung et al, 2005), with the aim to chart the prevalence of those who evolve to a first episode of psychosis. These individuals suffer from symptoms just below the threshold of clinical relevance (ultra high risk symptoms), or symptoms of perceptual or cognitive disorganization (basic symptoms; Schultze-Lutter and Koch, 2010) that are usually associated with a moderate degree of functional decline. It is thought that around $30 \%$ of individuals presenting such clinical high risk (CHR) go on to develop a full blown psychotic disorder (Nelson et al, 2013). Social cognitive impairments have been observed in this population, although it is still unclear if these impairments are related to their conversion towards psychosis. A longitudinal study investigating ToM in a group of 49 subjects at $\mathrm{CHR}$ for psychosis observed that $\mathrm{CHR}$ individuals who transitioned to psychosis displayed worse baseline scores on ToM tasks compared with non-converters (Kim et al, 2011). Moreover, the authors reported that a model combining both ToM and neurocognitive scores significantly predicted the time of transition to formal psychosis. Another recent study partly confirmed these results. Piskulic et al (2016) observed that a large CHR group $(n=764)$ displayed significantly worse performance in various domains of social cognition (ToM, social perception, facial emotion perception) compared to healthy controls $(n=280)$, yet no significant group differences emerged in any of the social cognitive domains between CHR individuals who transitioned to psychosis and their non-converting counterparts (Piskulic et al, 2016). Still, improvements in social cognition over time (one year followup) were more prominent in CHR non-converters and healthy controls compared to CHR converters.

In clinical states of first-episode psychosis, schizotypal personality disorder, or schizophrenia spectrum disorders, the evidence for social cognitive impairments is abundant (Green, Horan and Lee, 2015). A number of studies have reported impairments in mentalizing (Debbané et al, 2016a), metacognition (Lysaker, 2014), insight (Lysaker, 2014a), and other higher order cognitive processes (HOC). Importantly, these studies emphasize the relationship between HOC and social adaptive functioning in clinical states. Currently, metacognitive therapy for psychosis provides a model that suggests targeting reflective processes about self and others to remediate social cognitive dysfunction in psychotic disorders (Van Donkersgoed, 2014). Similarly, cognitive remediation strategies attempt to rescue social cognitive dysfunction which is thought to represent the principle obstacle for recovering a social functional role in individuals with recurring and chronic forms of psychotic illnesses. All 
these therapeutic strategies, we think, work with HOC because it is through these processes that the plasticity of mental functioning can be herded to restructure ingrained thinking patterns into less rigid intersubjective and interpersonal interpretative schemas. In other words, through the reconfiguration of a more flexible network of beliefs about oneself, together with the rekindling of interest in interpersonal and social relationships, patients may partly recover the tools necessary to regulate themselves within the sometimes overwhelming torments of interpersonal relationships.

\section{Conclusion}

Starting from our own experience in the clinical encounter and drawing on training, practice and research in the field of psychotherapy and psychosis, a number of conclusions may be tentatively offered: a) a secure experience of attachment with the caregiver(s) is paramount for the development of mentalizing, and may be protective against the effects of environmental risk factors, including trauma; b) effective therapists find it useful to reflect on their own experiences of attachment, and to be able to mentalize and create secure attachments with patients; c) being insecurely attached to care-givers and frequent exposure to relational stress are (two of many) vulnerability factors for psychosis; d) in this context, early screening and detection of high-risk states for psychosis are paramount for sustaining the development of flexible social cognitive processes; e) MBT may represent an effective tool in preventing the development of full blown psychosis through a resilience inducing process, although this needs to be tested empirically.

The development of psychotic disorders is a dynamic and multi-determined process. Despite the importance of genes (Arnedo et al, 2015) it is in the interaction between them and the environment that the disorder can progress. Investing in primary prevention programs could significantly reduce the burden of mental health problems. Work with infants, vulnerable mothers and adolescents at risk is needed to test the capacity of resilience-inducing mechanisms such as mentalizing to reduce the burden incurred by psychosis. Clinically, a sustained reflective stance facilitated by humble, curious, reflexive and attuned practitioners may critically contribute to ameliorating treatment along the psychosis continuum. 


\section{References}

Allen, J.G., Fonagy, P., and Bateman, A.W. (2008). Mentalizing in Clinical Practice. Washington: American Psychiatric Publishing, Inc.

Arnedo, J., Svrakic, D. M., Del Val, C., Romero-Zaliz, R., Hernan- dez-Cuervo, H., Genetics, Molecular, et al. (2015). Uncovering the hidden risk architecture of the schizophrenias: Confirmation in three independent genome-wide association studies. Am J Psychiatry, 172(2), 139-153.

Aron, L. (1996). A Meeting of Minds. Hillsdale: The Analytic Press

Badiou, A. (1989). Manifesto for Philosophy. New York: State University Press.

Baron-Cohen, S. (1995) Mindblindness: an essay on autism and Theory of Mind. Cambridge, MA: Bradford MIT Press.

Bartels-Velthuis, A. A., Blijd-Hoogewys, E. M., and van Os, J. (2011). Better theory-ofmind skills in children hearing voices mitigate the risk of secondary delusion formation. Acta Psychiatr. Scand. 124, 193-197. doi: 10.1111/j.1600- 0447.2011.01699.x

Bateman, A. W. and Fonagy, P. (2004) Psychotherapy for Borderline Personality Disorder: mentalization based treatment. Oxford: Oxford University Press.

Bateman, A. W. and Fonagy, P. (2006). Mentalization-Based Treatment for Borderline Personality Disorders - a practical guide. Oxford, Oxford University Press.

Bateman, A.W., and Fonagy, P. (2012). Handbook of Mentalizing in Mental Health Practice. Arlington: American Psychiatric Publishing.

Bateman, A.W., Fonagy, P., and Luyten, P. (2012). Introduction and Overview, in Handbook of Mentalizing in Mental Health Practice, ed. A.W. Bateman and Fonagy, P. (Arlington: American Psychiatric Publishing), 3-42

Bateman, A. W., O'Connell, J., Lorenzini, N., Gardner, T., \& Fonagy, P. (2016). A randomised controlled trial of mentalization-based treatment versus structured clinical management for patients with comorbid borderline personality disorder and antisocial personality disorder. BMC Psychiatry, 16(1), 936-12. http://doi.org/10.1186/s12888016-1000-9

Bateman, A.W., and Fonagy, P. (2016). Mentalization-Based Treatment for Personality Disorders: A Practical Guide. Oxford: Oxford University Press. 
Bion, W. R. (1962) Learning from Experience. London, Heinemann.

Brent, B. K. (2009). Mentalization-based psychodynamic psychotherapy for psychosis. Journal of Clinical Psychology, 65(8), 803-814.

Brent, B. K and Fonagy, P (2014). A Mentalization-Based Treatment Approach to Disturbances of Social Understanding in Schizophrenia. In: Social Cognition and Metacognition in Schizophrenia: Psychopathology and Treatment Approaches, Chapter: 15, Publisher: Elsevier Science \& Technology, Editors: Paul Lysaker, Giancarlo Dimaggio, Martin Brune, pp.245-259

Choi-Kain, L.W., and Gunderson, J.G. (2008). Mentalization: ontogeny, assessment, and application in the treatment of borderline personality disorder. Am J Psychiatry 165, 1127-1135. doi: 10.1176/appi.ajp.2008.07081360.

Clemmensen, L., van Os, J., Drukker, M., Munkholm, A., Rimvall, M. K., Vaever, M., et al. (2016). Psychotic experiences and hyper-theory-of-mind in preadolescence-a birth cohort study. Psychol. Med. 46, 87-101. doi: 10. 1017/s0033291715001567

Clemmensen, L., van Os, J., Skovgaard, A. M., Vaever, M., Blijd-Hoogewys, E. M., Bartels-Velthuis, A. A., et al. (2014). Hyper-theory-of-mind in children with Psychotic Experiences. PLoS One 9:e113082. doi: 10.1371/journal.pone. 0113082

Debbané, M., Van der Linden, M., Gex-Fabry, M., and Eliez, S. (2009). Cognitive and emotional associations to positive schizotypy during adolescence. J. Child Psychol. Psychiatry 50, 326-334. doi: 10.1111/j.1469-7610.2008.01961.x

Debbané, M., Van der Linden, M., Glaser, B., and Eliez, S. (2008). Source monitoring for actions in adolescents with 22q11.2 deletion syndrome (22q11DS). Psychol. Med. 38, 811-820. doi: 10.1017/S00332917070 0222X

Debbané, M., and Barrantes-Vidal, N. (2015). Schizotypy from a developmental perspective. Schizophr. Bull. 41, S386-S395. doi: 10.1093/schbul/sbu175

Debbané, M., Salaminios, G., Luyten, P., Badoud, D., Armando, M., Solida-Tozzi, A., et al. (2016). Attachment, Neurobiology, and Mentalizing along the Psychosis Continuum. Frontiers in Human Neuroscience, 10, 73-22. http://doi.org/10.3389/fnhum.2016.00406

Debbané, M., Benmiloud, J., Salaminios, G., Solida-Tozzi, A., Armando, M., Fonagy, P., \& Bateman, A. W. (2016a). Mentalization-Based Treatment in Clinical High-Risk for Psychosis: A Rationale and Clinical Illustration. Journal of Contemporary Psychotherapy, 1-9. http://doi.org/10.1007/s10879-016-9337-4

Fairbairn, W. R. D. (1952) An Object-Relations Theory of the Personality. New York, Basic Books. 
Fonagy, P. (1991) Thinking about thinking: some clinical and theoretical considerations in the treatment of a borderline patient. International Journal of Psycho-Analysis, 72, 639-656.

Fonagy, P., Gergely, G., Jurist, E. L. and Target, M. (2002) Affect Regulation, Mentalization, and the Development of the Self. New York, Other Press.

Fonagy, P., Lorenzini, N., Campbell, C. \& Luyten, P. (2014) Why are we interested in attachments? In the Routledge Handbook of Attachment Theory. Eds Holmes, P., Farnfield, S. Routledge: New York.

Fonagy, P. and Allison, E. (2014). The role of mentalizing and epistemic trust in the therapeutic relationship. Psychotherapy (Chic) 51, 372-380. doi: 10.1037/a0036505.

Fonagy, P., \& Bateman, A. W. (2016). Adversity, attachment, and mentalizing. Compr Psychiatry, 64, 59-66.

Foucault, M. (1975). Surveiller et Punir: naissance de la prison. Paris : Gallimard.

Foucault, M. (1972). Histoire de la Folie a L'Age Classic. Paris: Gallimard.

Freud, S. (1895) Project for a scientific psychology. In: Strachey, J. (ed.) The Standard Edition of the Complete Psychological Works of Sigmund Freud (S. E.), Vol. 1. Hogarth Press, London, pp. 283-397.

Freud, S. (1914) On Narcissism: an introduction. In: Strachey, J. (ed.) The Standard Edition of the Complete Psychological Works of Sigmund Freud (S. E.), Vol. 14. Hogarth Press, London, 67-104.

Freud, S. (1933) New Introductory Lectures on Psycho-Analysis. The Standard Edition of the Complete Psychological Works of Sigmund Freud, Volume XXII, pp.1-182.

Ghent, E (1989). Credo: the dialectics of one-person and two-person psychologies. Contemporary Psychoanalysis, 25, pp 200-237.

Gilbert and Orlans (2011). Integrative Therapy: 100 key points and techniques. Routledge: London.

Goerlich, K. S., Aleman, A., Martens, S. and Hooker, C. (manuscript in preparation) I Know How You'll Feel: affective mentalizing in alexithymia, an fMRI study. [Online]. 
Available from dissertations.ub.rug.nl/FILES/faculties/medicine/2011/k.s.../05c5.pdf [Accessed 23 ${ }^{\text {rd }}$ March 2016].

Goffman, E. (1959) The Presentation of Self in Everyday Life. New York. Anchor Books.

Green, M. F., Horan, W. P., \& Lee, J. (2015). Social cognition in schizophrenia. Nature Reviews Neuroscience, 16(10), 620-631. http://doi.org/10.1038/nrn4005

Heidegger, M. (1962) Being and Time. Oxford: Blackwell Publishing.

Jewell, T., Collyer, H., Gardner, T., Tchanturia, K., Simic, M., Fonagy, P., \& Eisler, I. (2015). Attachment and mentalization and their association with child and adolescent eating pathology: A systematic review. The International Journal of Eating Disorders, 49(4), 354-373. http://doi.org/10.1002/eat.22473

Jurist, E. L., Slade, A., and Bergner, S. (2008) Mind to Mind; Infant Research, Neuroscience, and Psychoanalysis. New York: Other Press.

Kim, H. S., Shin, N. Y., Jang, J. H., Kim, E., Shim, G., Park, H. Y., et al. (2011). Social cognition and neurocognition as predictors of conversion to psychosis in individuals at ultra-high risk. Schizophr. Res. 130, 170-175. doi: 10.1016/j. schres.2011.04.023

Klein, M. (1945) The Oedipus complex in the light of early anxieties. In: Love, Guilt and Reparation and Other Works: The Writings of Melanie Klein, Vol. 1. Hogarth Press, London, 1975, pp. 370-419.

Kohut, H. (1977). The Restoration of the Self. New York: International Universities Press.

Luyten, P., van Houdenhove, B., Lemma, A., Target, M., \& Fonagy, P. (2012). A mentalization-based approach to the understanding and treatment of functional somatic disorders. Psychoanalytic Psychotherapy, 26(2), 121-140. http://doi.org/10.1080/02668734.2012.678061

Lysaker, P. H., Leonhardt, B. L., Pijnenborg, M., van Donkersgoed, R., de Jong, S., \& Dimaggio, G. (2014). Metacognition in schizophrenia spectrum disorders: methods of assessment and associations with neurocognition, symptoms, cognitive style and function. The Israel Journal of Psychiatry and Related Sciences, 51(1), 54-62. 
Lysaker, P. H., Vohs, J., Hillis, J. D., Kukla, M., Popolo, R., Salvatore, G., \& Dimaggio, G. (2014a). Poor insight into schizophrenia: contributing factors, consequences and emerging treatment approaches. Expert Review of Neurotherapeutics, 13(7), 785-793. http://doi.org/10.1586/14737175.2013.811150

Marty, P. (1968). A major process of somatization: The progressive disorganization. International Journal of Psychoanalysis 49, 246-249.

Marty, P. (1991). Mentalisation et Psychosomatique. Paris: Synthélabo.

Mitchell, S. (2000). Relationality. Hillsdale, NJ: The Analytic Press.

Nelson, B., Yuen, H. P., Wood, S. J., Lin, A., Spiliotacopoulos, D., Bruxner, A., et al. (2013). Long-term follow-up of a group at ultra high risk ("prodromal") for psychosis: The PACE 400 study. [Evaluation studies research support, non-US Gov't]. JAMA Psychiatry, 70(8), 793-802

Pereira, J. G. (2010). Transference and the therapeutic relationship - working for or against it? Grupanaliseonline [online] Available at: $<$ http://grupanalise.pt/en/images/stories/revistaonline ingls/Transference and the The rapeutic Relationship working for or against it.pdf> [Accessed 14 November 2016].

Pereira, J. G. (2015). An Integrative-Relational Framework of Intervention at Casa de Alba: therapeutic community for severe mental health problems. British Journal of Psychotherapy Integration, Vol 11 (2), 37-52.

Peters, E., Ward, T., Jackson, M., Morgan, C., Charalambides, M., McGuire, P., et al. (2016). Clinical, socio-demographic and psychological characteristics in individuals with persistent psychotic experiences with and without a "need for care". World Psychiatry : Official Journal of the World Psychiatric Association (WPA), 15(1), 41-52. http://doi.org/10.1002/wps.20301

Piskulic, D., Liu, L., Cadenhead, K. S., Cannon, T. D., Cornblatt, B. A., McGlashan, T. H., et al. (2016). Social cognition over time in individuals at clinical high risk for psychosis: findings from the NAPLS-2 cohort. Schizophr. Res. 171, 176-181. doi: 10.1016/j.schres.2016.01.017

Read, J., and Gumley, A. (2010). "Can attachment theory help explain the relationship between childhood adversity and psychosis?" in Telling Stories? Attachment Based Approach to the Treatment of Psychosis, ed. S. Benamer (London: Karnac Books), 51- 
94.

Rudrauf, D. (2014). Structure-function relationships behind the phenomenon of cognitive resilience in neurology: Insights for neuroscience and medicine. Adv Neurosci, 4, 1-28

Sartre, J. P. (1992). Being and Nothingness. New York: Gallimard (first published in 1943).

Schultze-Lutter, F., and Koch, E. (2010). Schizophrenia Proneness Instrument: Child and Youth Version (SPI-CY). Rome: Fioriti.

Stolorow, R. and Atwood, G. (1992). Contexts of Being: the intersubjective foundations of psychological life. Hillsdale NJ: The Analytic Press.

Van Donkersgoed, R. J. M., De Jong, S., Van der Gaag, M., Aleman, A., Lysaker, P. H., Wunderink, L., et al. (2014). A manual-based individual therapy to improve metacognition in schizophrenia: Protocol of a multi-center RCT. BMC Psychiatry, 14, 27.

Weijers, J., Kate, ten, C., Eurelings-Bontekoe, E., Viechtbauer, W., Rampaart, R., Bateman, A. W., \& Selten, J.-P. (2016). Mentalization-based treatment for psychotic disorder: protocol of a randomized controlled trial. BMC Psychiatry, 1-10. http://doi.org/10.1186/s12888-016-0902-x

Winnicott, D. W. (1962) Ego integration in child development. In: The Maturational Processes and Facilitating Environment. Hogarth Press, London, pp. 56-63.

Wittgenstein, L. (1953) Philosophical Investigations. Malden: Blackwell.

Yung, A. R., Yuen, H. P., McGorry, P. D., Phillips, L. J., Kelly, D., Dell'Olio, M., et al. (2005). Mapping the onset of psychosis: the comprehensive assessment of at-risk mental states. Aust. N. Z. J. Psychiatry 39, 964-971. doi: 10.1080/j. 14401614.2005.01714.x 